\section{(6) OPEN ACCESS}

\title{
Severe hypophosphataemia after intravenous iron administration
}

\author{
Gurpreet Anand, Christoph Schmid
}

Division of Endocrinology, University Hospital Zürich, Zürich, Switzerland

\section{Correspondence to} Professor Christoph Schmid, christoph.schmid@usz.ch

Accepted 25 February 2017

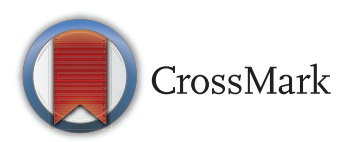

To cite: Anand $\mathrm{G}$ Schmid C. BMJ Case Rep Published online: [please include Day Month Year] doi:10.1136/bcr-2016219160

\section{SUMMARY}

Iron deficiency is common and can be effectively treated with parenteral iron infusion. We report a case of an iron-deficient and vitamin D-deficient woman who developed severe symptomatic hypophosphataemia following intravenous ferric carboxymaltose administration. We stress the need of increased awareness of this potential complication among physicians. Patients should be informed of this complication and instructed to report for follow-up if they experience new musculoskeletal symptoms or worsening of tiredness. As severe hypophosphataemia is usually symptomatic, we recommend screening symptomatic patients for this complication. Recognising and treating the possible exacerbating factors, especially vitamin $D$ deficiency, might be a simple measure to mitigate this complication.

\section{BACKGROUND}

There are many indications for parenteral iron administration such as chronic kidney disease, heart failure, inflammatory bowel disease and postbariatric surgery. Iron deficiency with or without anaemia is, however, most prevalent in the otherwise healthy menstruating women. The parenteral route is also preferred in these patients since oral iron has low bioavailability and can cause gastrointestinal side effects. ${ }^{1}$

Ferric carboxymaltose is one of the most commonly used parenteral iron formulations because of the ease of administration of a relatively large dose in a single infusion (up to $1 \mathrm{~g}$ of elemental iron) and fewer allergic side effects when compared with older iron preparations.

Severe hypophosphataemia has been described as a potential complication of certain parenteral iron formulations (such as ferric carboxymaltose, saccharated ferric oxide). ${ }^{2-11}$ In 2008, FDA reported that $2.1 \%$ of patients treated with ferric carboxymaltose developed hypophosphataemia, but severe hypophosphataemia was rare. Mild hypophosphataemia is mentioned as a common complication in product labelling information of ferric carboxymaltose, but not widely acknowledged. ${ }^{12}$ Recently, Schaefer $e a^{13}$ revealed high prevalence of severe hypophosphataemia $(32.1 \%)$ after treatment of iron deficiency with high-dose intravenous ferric carboxymaltose in a patient population with gastrointestinal disorders.

\section{CASE PRESENTATION}

A woman of Mexican origin aged 38 years was referred to our clinic for the evaluation of tiredness, diffuse muscle pain and weakness for the past year. She was advised to get her adrenal function checked in a consultation in her own country, which is why she specifically asked for a referral to an endocrinology clinic. She had no family history of bone or mineral metabolism disorders. She grew and developed normally as a child, and denied alcohol consumption and smoking. Her general physician detected iron deficiency anaemia 7 weeks before consultation in our clinic; ferritin was $7.8 \mu \mathrm{g} / \mathrm{L}(13-150)$ and haemoglobin $111 \mathrm{~g} / \mathrm{L}(117-$ 153). At the same time, vitamin $B_{12}$ was $146 \mathrm{pmol} /$ $\mathrm{L}(>220)$. She received an intramuscular injection of $1 \mathrm{mg}$ vitamin 12 injection the next day ( 2 weeks before the first iron administration). Her folate levels were not measured.

She was treated with parenteral ferric carboxymaltose at a dose of $500 \mathrm{mg}$ which was given twice (4, respectively, 3 weeks before presentation to our clinic). The cause of her iron deficiency anaemia was heavy menstrual bleeding, for which her gynaecologist inserted a levonorgestrelcontaining IUD before her first presentation in our clinic.

Her history revealed intravenous iron administration 1 year before. Interestingly, she reported no symptom relief after iron administration recently as well as in the past. She reported an exacerbation of her muscle pain and weakness after her previous iron infusion. Her complaints and symptoms were believed to be manifestation of depression.

Physical examination findings were as follows: height $145 \mathrm{~cm}$ (within her midparental range), weight $54 \mathrm{~kg}$, BMI $25.8 \mathrm{~kg} / \mathrm{m}^{2}$, blood pressure $125 /$ $80 \mathrm{~mm} \mathrm{Hg}$, pulse $80 / \mathrm{min}$ with normal cardiac and pulmonary auscultation findings. The abdominal examination revealed slight tenderness in the right midabdomen with normal bowel sounds. Her overall appearance did not indicate any bone or facial deformity.

\section{INVESTIGATIONS}

Laboratory tests on presentation (table 1 , day 0 ) revealed severe hypophosphataemia, $0.23 \mathrm{mmol} / \mathrm{L}$ (0.87-1.45), a slightly low albumin-adjusted calcium, $1.99 \mathrm{mmol} / \mathrm{L} \quad(2.09-2.54)$ and a low 25-hydroxy-vitamin $\quad \mathrm{D}, \quad 12 \mu \mathrm{g} / \mathrm{L} \quad$ (recommended value $>20$ ).

Coeliac screening was negative. Liver enzymes were not elevated. Serum ferritin was $662 \mu \mathrm{g} / \mathrm{L}$ (reflecting the recent iron infusions). Haemoglobin was normalised $(124 \mathrm{~g} / \mathrm{L})$. Creatinine was in the low normal range, $42 \mu \mathrm{mol} / \mathrm{L}$ (44-80). Morning cortisol was $324 \mathrm{nmol} / \mathrm{L}$, which together with 
Table 1 Evolution of laboratory values since presentation in our clinic

\begin{tabular}{llllll}
\hline Days since presentation & $\mathbf{0}$ & $\mathbf{2}$ & $\mathbf{2 5}$ & $\mathbf{5 1}$ & $\mathbf{1 0 1}$ \\
\hline $\begin{array}{l}\text { Calcium, albumin-corrected } \\
\text { (2.09-2.54 mmol/L) }\end{array}$ & 1.99 & 2.05 & 2.22 & 2.21 & 2.15 \\
Phosphate $(0.87-1.45 \mathrm{mmol} / \mathrm{L})$ & 0.23 & 0.30 & 0.93 & 1.06 & 1.17 \\
Creatinine $(44-80 \mu \mathrm{mol} / \mathrm{L})$ & 42 & 40 & 52 & 43 & 45 \\
PTH (15-65 ng/L) & 52.7 & 69.5 & 46.5 & 46.3 & \\
25-hydroxyvitamin D (>20 $\mu \mathrm{g} / \mathrm{L})$ & 12 & & & & 28 \\
1,25-dihydroxy-vitamin D (26.1-95 ng/L) & & 23.8 & 74.8 & 71.8 & \\
TmP/GFR $(0.8-1.35 \mathrm{mmo} / \mathrm{L})$ & & 0.21 & 0.83 & 0.91 & \\
\hline
\end{tabular}

The patient presented with hypophosphataemia on day 0 (which was 3 weeks following the last intravenous administration of ferric carboxymaltose), and hypophosphataemia was confirmed on day 2, along with the finding of increased renal phosphate loss and a low calcitriol.

normal serum sodium and potassium values and lack of specific symptoms (no hyperpigmentation and weight loss) made primary adrenal insufficiency an unlikely diagnosis. There was no history of glucocorticoid use in the past.

Along with confirming hypophosphataemia (day 2), we investigated its cause. We measured the concentration of phosphate and creatinine in a fasting spot urine sample to evaluate renal phosphate transport by calculating TmP/GFR. This value corresponds to the theoretical lower limit of plasma phosphate below which all filtered phosphate would be absorbed (normal range, $0.80-1.35 \mathrm{mmol} / \mathrm{L})$.

$$
\text { TmP/GFR in mmol/L }=\mathrm{P}_{\mathrm{p}}-\left[\mathrm{U}_{\mathrm{p}} \times \mathrm{P}_{\text {crea }} / \mathrm{U}_{\text {crea }}\right]
$$

where $\mathrm{P}_{\mathrm{P}}, \mathrm{U}_{\mathrm{P}}, \mathrm{P}_{\text {Crea }}$ and $\mathrm{U}_{\text {Crea }}$ refer to the plasma and urinary concentration of phosphate and creatinine, respectively. ${ }^{14}$

A low value indicates renal phosphate wasting. In our patient, it was $0.21 \mathrm{mmol} / \mathrm{L}$.

Intact parathyroid hormone (PTH) was slightly increased, $69.5 \mathrm{ng} / \mathrm{L}$ (15-65), presumably as an adaptive response to vitamin D deficiency. Her calcium was low due to vitamin D deficiency. Alkaline phosphatase and its bone-specific isoform were not elevated, suggesting that her hypophosphataemia was probably of recent onset and did not result in a serious mineralisation disorder.

The absence of albuminuria and glucosuria ruled out a generalised proximal tubular disorder (Fanconi syndrome). 1,25-dihydroxyvitamin D was low, $23.8 \mathrm{ng} / \mathrm{L}$ (26.1-95), which in the face of hypophosphataemia suggested excessive fibroblast growth factor 23 (FGF23) to be the cause of increased renal phosphate excretion since FGF23 promotes renal phosphate loss and impairs 1- $\alpha$-hydroxylation of vitamin D.

\section{TREATMENT}

We started vitamin D replacement with $2000 \mathrm{IU} /$ day for 4 weeks and continued with $1000 \mathrm{IU} /$ day thereafter. She was also treated with calcitriol $0.25 \mu \mathrm{g}$ two times per day for a total duration of 36 days.

\section{OUTCOME AND FOLLOW-UP}

Our patient reported relief of her tiredness, muscle pain and weakness on vitamin $\mathrm{D}$ replacement and calcitriol within 2 days of starting the treatment. Phosphate values normalised under treatment and remained normal 1 week after stopping calcitriol (table 1). At the same time 1,25-dihydroxyvitamin D was high normal. Vitamin D replacement was continued. 25-hydroxyvitamin D levels normalised in the follow-up 3 months later. Her monthly bleeding reduced after insertion of levonorgestrel-containing IUD. Haemoglobin and ferritin values remained stable in the follow-up 3 months later.

\section{DISCUSSION}

In our case, hypophosphataemia was severe, prolonged and symptomatic. Low TmP/GFR confirmed that hypophosphataemia was due to renal phosphate wasting which can occur in proximal tubular disorders, in hyperparathyroidism and in disorders of FGF23 excess. We excluded Fanconi syndrome. Secondary hyperparathyroidism (calcium was low normal) causes only mild renal phosphate loss and is associated with high normal 1,25-dihydroxyvitamin D levels. FGF23 excess appeared to be the most likely cause of renal phosphate wasting.

Disorders of FGF23 excess can be either acute or chronic. Chronic FGF23 excess as in tumour-induced osteomalacia is usually associated with mineralisation disorder reflected by increased bone-specific alkaline phosphatase. ${ }^{15}$ This was not the case in our patient.

Our patient received ferric carboxymaltose infusion twice, making increased FGF23 activity the most likely cause of hypophosphataemia as supported by renal phosphate wasting and low 1,25-dihydroxyvitamin D. ${ }^{10} 15$

Hypovitaminosis D was detected but not treated by her physician before iron administration, making baseline hypophosphataemia (and secondary hyperparathyroidism) as a probable additional risk factor. However, phosphate values were not measured.

Increased erythropoiesis after correction of iron deficiency could also result in mild hypophosphataemia by increased cellular uptake of phosphate, but this would not explain increased renal phosphate loss. ${ }^{11}$

FGF23 is a phosphatonin secreted by osteocytes leading to phosphate wasting through inhibition of $\mathrm{Na}^{+}$-dependent phosphate cotransporters in the proximal renal tubules. Iron deficiency per se increases FGF23 transcription as well as its degradation. Administration of ferric carboxymaltose inhibits FGF23 degradation and thereby increases the biologically active FGF23, which then can cause hypophosphataemia. ${ }^{2-11}$ Owing to the complex interplay of different FGF23 forms and their processing in iron deficiency, measuring FGF23 values is not recommended in clinical practice. Furthermore, FGF23 assays are not routinely available and expensive. TmP/GFR and 1,25-dihydroxyvitamin $\mathrm{D}$ are simple tests providing useful information about the mechanism of hypophosphataemia in severe cases.

The nadir of serum phosphate is usually reached 2 weeks after administration of intravenous iron. The median time to normalisation of phosphate after a single iron infusion is 84 days, but may be prolonged after repetitive iron infusions. ${ }^{13}$

Vitamin D deficiency should be screened and corrected in all patients. Calcitriol cannot correct FGF23 excess, but its replacement plays an important role as it helps to increase intestinal phosphate absorption, attenuates secondary hyperparathyroidism and thereby corrects and shortens the duration of hypophosphataemia. 1,25-dihydroxyvitamin D was low at baseline reflecting the suppressive effect of FGF23 on 1- $\alpha$-hydroxylation of vitamin D. We also chose calcitriol in our patient since phosphate and calcium were low (and PTH elevated presumably due to coexisting vitamin $\mathrm{D}$ deficiency). Also in patients with normal vitamin $\mathrm{D}$ status and normal calcium values, calcitriol can be considered as 1,25-dihydroxyvitamin D levels are low 
due to excessive FGF23 activity. As our patient responded well to calcitriol, we did not give phosphate supplementation. Additionally, large amount of phosphate needed to correct hypophosphataemia in renal phosphate wasting often cause gastrointestinal side effects.

Considering the expanding use of intravenous iron, we hope our case contributes to the awareness of general physicians as well as specialists for this potential complication. Patients should be informed and instructed to report for follow-up if they experience new musculoskeletal symptoms or worsening of tiredness.

Recently, Schaefer et $a l^{13}$ found significantly less hypophosphataemia with ferric isomaltoside (not yet available in our country) compared with ferric carboxymaltose. This iron form might be preferred in patients prone to hypophosphataemia. However, risk of hypersensitivity reactions is higher with ferric isomaltoside. The possibility of different side effects needs to be carefully considered and balanced. ${ }^{16}$

\section{Patient's perspective}

I always wanted to know the reason for my tiredness and muscle pain, which actually worsened after getting iron infusion. I never felt any depression, which was initially thought to be the cause of my symptoms. I am happy to know the cause of my symptoms now. The treatment immediately worked as an energy boost. Now I work and do daily activities as a normal person.

\section{Learning points}

- Clinicians prescribing ferric carboxymaltose should be aware of the potential complication of hypophosphataemia.

- Serum phosphate levels should be measured at least in symptomatic patients after administration of iron infusion. Cause of severe hypophosphataemia can be determined by estimating TmP/GFR and 1,25-dihydroxyvitamin D.

- Correction of coexisting vitamin D deficiency could be a simple measure to mitigate hypophosphataemia.

- Hypophosphataemia, if symptomatic and severe, can be treated with calcitriol and possibly phosphate supplements until its remission.
Contributors GA planned, wrote and edited the case report. She also treated the patient. CS provided guidance in all steps and edited the case report.

Competing interests None declared.

\section{Patient consent Obtained.}

Provenance and peer review Not commissioned; externally peer reviewed.

Open Access This is an Open Access article distributed in accordance with the Creative Commons Attribution Non Commercial (CC BY-NC 4.0) license, which permits others to distribute, remix, adapt, build upon this work non-commercially, and license their derivative works on different terms, provided the original work is properly cited and the use is non-commercial. See: http://creativecommons.org/ licenses/by-nc/4.0/

\section{REFERENCES}

1 Hempel EV, Bollard ER. The evidence-based evaluation of iron deficiency anemia. Med Clin North Am 2016;100:1065-75.

2 Okada M, Imamura K, Fuchigami T, et al. 2 cases of nonspecific multiple ulcers of the small intestine associated with osteomalacia caused by long-term intravenous administration of saccharated ferric oxide. Nippon Naika Gakkai Zasshi 1982:71:1566-72.

3 Schouten B, Hunt P, Livesey J, et al. FGF23 elevation and hypophosphatemia after intravenous iron polymaltose. JCEM 2009:94:2332-7.

4 Shimizu Y, Tada Y, Yamauchi M, et al. Hypophosphatemia induced by intravenous administration of saccharated ferric oxide: another form of FGF23-related hypophosphatemia. Bone 2009;45:814-16

5 Van Wyck DB, Mangione A, Morrison J, et al. Large-dose intravenous ferric carboxymaltose injection for iron deficiency anemia in heavy uterine bleeding. Transfusion 2009;49:2719-28.

6 Yamamoto S, Okada Y, Mori H, et al. Fibroblast growth factor 23-related osteomalacia caused by the prolonged administration of saccharated ferric oxide. Intern Med 2012:51:2375-8.

7 Wolf M, Koch TA, Bregman DB. Effects of iron deficiency anemia and its treatment on fibroblast growth factor 23 and phosphate homeostasis in women. J Bone Miner Res 2013;28:1793-803

8 Hu MC, Shiizaki K, Kuro-o M, et al. Fibroblast growth factor 23 and klotho: physiology and pathophysiology of an endocrine network of mineral metabolism. Annu Rev Physiol 2013;75:503-33.

9 Blazevic A, Hunze J, Boots JM. Severe hypophosphaetemia after intravenous iron administration. Neth J Med 2014;72:49-53.

10 Vandemergel $X$, Vandergheynst F. Potentially life-threatening phosphate diabetes induced by ferric carboxymaltose injection. Case Rep Endocrinol 2014; 2014:843689.

11 Hardy S, Vandemergel X. Intravenous iron administration and hypophosphatemia in clinical practice. Int J Rheumatol 2015:2015:468675.

12 Glendenning P, Bell DA, Clifton-Bligh RJ. Investigating hypophosphataemia. BMJ 2014:348:g3172.

13 Schaefer $B$, Würtinger $P$, Finkenstedt $A$, et al. Choice of high-dose intravenous iron preparation determines hypophosphatemia risk. PLOS ONE 2016;11: e0167146.

14 Brodehl J, Krause A, Hoyer PF. Assessment of maximal tubular phosphate reabsorption: comparison of direct measurement with the nomogram of Bijvoet Pediatr Nephrol 1988;2:183-9.

15 Bauer C, Brücker R, Bützberger $S$, et al. Hypophosphataemia-inducing mesenchymal tumour in the foot. BMJ Case Rep 2010;2010:pii:bcr0620092034

16 Bager P, Hvas CL, Dahlerup JF. Drug-specific hypophosphatemia and hypersensitivity reactions following different intravenous iron infusions. Br J Clin Pharmacol 2016.

Copyright 2017 BMJ Publishing Group. All rights reserved. For permission to reuse any of this content visit

http://group.bmj.com/group/rights-licensing/permissions.

BMJ Case Report Fellows may re-use this article for personal use and teaching without any further permission.

Become a Fellow of BMJ Case Reports today and you can:

- Submit as many cases as you like

- Enjoy fast sympathetic peer review and rapid publication of accepted articles

- Access all the published articles

- Re-use any of the published material for personal use and teaching without further permission

For information on Institutional Fellowships contact consortiasales@bmjgroup.com

Visit casereports.bmj.com for more articles like this and to become a Fellow 